\title{
REVISTAMARACANAN
}

\section{Poderes, trajetórias e administração no Império português (séculos XVI-XVIII)}

Powers, trajectories and administration in the Portuguese Empire (16th-18th centuries)

\section{Apresentação}

\author{
Rafael Ricarte da Silva* \\ Universidade Federal do Piauí \\ Picos, Piauí, Brasil \\ Reinaldo Forte Carvalho** \\ Universidade de Pernambuco \\ Petrolina, Pernambuco, Brasil
}

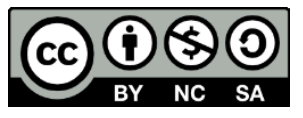

\footnotetext{
* Professor Adjunto do curso de História da Universidade Federal do Piauí, Campus Senador Helvídio Nunes de Barros. Doutor e Mestre em História Social e licenciado em História pela Universidade Federal do Ceará; Especialista em Planejamento, Implementação e Gestão da Educação a Distância pela Universidade Federal Fluminense. (rafa-ricarte@hotmail.com)

(iD) https://orcid.org/0000-0003-4085-5401 (9) http://lattes.cnpq.br/1472762122361574

** Professor Adjunto do curso de História da Universidade de Pernambuco, Campus Petrolina. Doutor em História pela Universidade Federal de Pernambuco; Mestre em História e Culturas pela Universidade Estadual do Ceará; Licenciado em História pela Universidade Federal do Ceará. (reinaldoforte@yahoo.com.br)

(iD) https://orcid.org/0000-0001-7930-8670

(9) http://lattes.cnpq.br/4435223781591585
} 
O presente dossiê tem como objetivo promover a produção científica e o debate sobre as relações de poder, as trajetórias e os conflitos entre os diversos representantes, oficiais e agentes régios no Império português entre os séculos XVI e XVIII. Relações essas que vão se dar a partir das dinâmicas presentes no âmbito das representações políticas, econômicas e socioculturais das instituições administrativas na América portuguesa.

Os estudos historiográficos acerca do estabelecimento de instituições (administrativas, religiosas, militares, etc.) e as relações de poder constituídas nas mais diversas escalas ganharam, nas últimas décadas, novos olhares a partir do constante diálogo com pesquisas desenvolvidas por historiadores estrangeiros, a incorporação de novas fontes documentais, aportes teórico-metodológicos e a constituição de bases de dados por grupos de pesquisas nas universidades brasileiras. ${ }^{1}$ Desta maneira, este dossiê pretende aprofundar o debate sobre os poderes e as instituições constituídas na América portuguesa, enfocando: as redes de alianças políticas e econômicas, os espaços de poder, a fixação de instâncias administrativas, jurídicas e religiosas, regulação legislativa e a dinâmica local, comunicação e correspondência no império português, poder local e hierarquia administrativa, agentes coloniais/metropolitanos e suas trajetórias, poder e distinção social, disputas de jurisdição, fiscalidade e justiça. Estas temáticas estão presentes nas pesquisas que compõem este dossiê e nos permitem a compreensão dos múltiplos poderes constituídos a partir das diversas experiências particulares e coletivas vivenciadas no espaço colonial.

Neste sentido, o primeiro artigo do dossiê de autoria de Hugo André Flores Fernandes Araújo, "Casa, serviço e memória: origens sociais, carreira e estratégias de acrescentamento social dos governadores-gerais do Estado do Brasil (Século XVII)" propõe uma reflexão sobre as trajetórias sociais de sujeitos históricos que serviram a Coroa portuguesa em diversos territórios, problematizando o perfil característico deste grupo por meio das fontes e do diálogo com a historiografia.

As trajetórias sociais e administrativas também compõem o eixo de reflexão proposto por Tânia Maria Pinto de Santana para analisar a administração do Hospital de São João de Deus. A autora de "Império português, poderes locais e a administração do Hospital de São João de Deus da Vila de Cachoeira (Bahia, séc. XVIII)" investiga as práticas administrativas na

${ }^{1}$ Cf.: FRAgOSO, J.; BICALHO, M. F.; GOUVÊA, M. de F. (orgs.). Antigo Regime nos Trópicos: A Dinâmica Imperial Portuguesa. Rio de Janeiro: Civilização Brasileira, 2001; SAMPAIO, A. C. J.; ALMEIDA, C. M. C.; FRAGOSO. J. Conquistadores e negociantes: histórias de elites no Antigo Regime nos trópicos: América lusa, séculos XVI a XVIII. Rio de Janeiro: Civilização Brasileira, 2007; FRAGOSO, J.; GOUVÊA, M. F. (orgs.). Na trama das redes: política e negócio no império português, séculos XVI-XVIII. Rio de Janeiro: Civilização Brasileira, 2010; FRAGOSO, J.; SAMPAIO, A. C. J. (orgs.). Monarquia pluricontinental e a governança da terra no ultramar atlântico luso: Séculos XVI-XVIII. Rio de Janeiro: Mauad X, 2012; VENÂNCIO, R. P.; GONÇALVES, A. L.; CHAVES, C. M. D. G. (orgs.). Administrando impérios: Portugal e Brasil nos séculos XVIII e XIX. Belo Horizonte: Fino Traço, 2012; FRAGOSO, J.; GOUVÊA, M. (orgs.). O Brasil Colonial. Rio de Janeiro: Civilização Brasileira, 2014. 3 vols.; dentre outros. 
referida instituição com vistas a perceber a importância deste espaço de poder para as elites locais.

Seguindo o eixo de análise acerca das trajetórias, o artigo intitulado "A trajetória de Pedro Barbosa Leal e as redes de conquistas no sertão da capitania da Bahia, 1690-1730" de Hélida Santos Conceição, evidência a trajetória do coronel e sertanista Pedro Barbosa Leal por meio do arrolamento de seus serviços prestados no processo de conquista dos sertões da Bahia. Ademais, a autora aponta o caso singular deste agente inserido nos espaços da nobreza e na atividade sertanista.

A constituição de um correio mensal entre São Luís e Belém por volta de 1730 é investigada por Romulo Valle Salvino em "Um correio pelo caminho de terra: as comunicações no estado do Maranhão e Grão-Pará nos princípios do século XVIII". Para o autor, a instituição deste canal de comunicação pelo Governador do Estado do Maranhão e Grão-Pará, Alexandre de Sousa Freire, desenvolveu-se como um pioneirismo. A análise deste caso particular é realizada a partir da historicidade do sistema de correios do período moderno.

O artigo, "A Restauração de Angola e os pedidos de mercês no século XVII", de Ingríd Silva de Oliveira Leite finaliza a seção de artigos do dossiê. A autora busca analisar o processo de requisição de mercês a Coroa portuguesa no contexto da Restauração de Angola, objetivando compreender a prestação dos serviços no conflito frente aos holandeses, a solicitação das mercês, o mapeamento destes sujeitos e se os mesmos foram agraciados em suas demandas.

As entrevistas realizadas com o professor Dr. George Felix Cabrall e com a professora Dra. Laurinda Abreu também compõem o presente dossiê. A primeira delas, realizada pelos organizadores desta edição com o professor de História da Universidade Federal de Pernambuco, procura debater as percepções da História e seus desafios na contemporaneidade. A segunda entrevista, realizada por Thiago Enes com a professora da Universidade de Évora, aborda a "A controversa trajetória de Diogo Inácio de Pina Manique, Intendente-Geral da Polícia da Corte e do Reino", conforme título.

A seção Notas de Pesquisa é composta por três estudos. A publicação do excelente estudo de Wanderley de Oliveira Menezes sobre "Administrar a justiça d'El Rei no Reino e no Ultramar: a trajetória do bacharel José Álvares Ferreira (1772-1810)" abre a seção dialogando com o eixo temático proposto neste dossiê acerca dos poderes, trajetórias e administração no Império português. Em seguida, os trabalhos de Sheilla Hempkemeyer sobre "Cidades e corpos - Histórias e movimentos"; e o de Amanda Peruchí, intitulado "Abelhas ou Zangões: as primeiras normas para o profissional da farmácia do Brasil no início do século XIX" finalizam as notas de pesquisa.

A seção artigos conta com alguns estudos de temáticas diversas e importantes para contribuir com essa publicação, a saber: "Visitando obras historiográficas do Império Lusitano na Oceania: Um recorte da história de Timor-Leste", de Hélio José Santos Maia \& Urânia Auxiliadora Santos Maia de Oliveirra; "Os artífices do poder: mecanismos de ascensão social em Guarapiranga (MG), 1715-1820", de Débora Cristina Alves; "No fio da navalha: a 
questão do tráfico internacional de escravos no Conselho de Estado" de Ricardo Bruno da Silva Ferreira; "Tráfico de escravos e escravidão na trajetória do Barão de Nova Friburgo Século XIX", de autoria de Rodrigo Marins Marretto; "O que a cidade de Ipásia tem a nos dizer sobre pixação? Leituras possíveis de As Cidade Invisíveis, de Ítalo Calvino, e São Paulo/SP", de Bianca Siqueira Martins Domingos, Fabiana Felix do Amaral \& Silva e Valéria Regina Zanetti; "Imagens em versos e acordes: a representação da cidade de Feira de Santana através do seu hino", de autoria de Aldo José Morais Silva; "A cidade 'perigosa' e sua instituição 'tranquilizadora': o Recife no contexto da reforma prisional do Oitocentos", de Aurélio de Moura Britto; e, "As cidades e suas contribuições para o donativo do dote e paz", de autoria de Letícia dos Santos Ferreira.

Por fim, a edição conta ainda com a resenha de Igor Lemos Moreira sobre o livro $A$ formação da coleção latino-americana do MoMA: Arte, cultura e política (1931-1943), publicado em 2019 pela Paco Editorial.

Boa leitura! 


\section{Referências}

FRAGoso, J.; BICALHO, M. F.; GOUVÊA, M. F. (orgs.). Antigo Regime nos Trópicos: A Dinâmica Imperial Portuguesa. Rio de Janeiro: Civilização Brasileira, 2001.

FRAGOSO, J.; GOUVÊA, M. (orgs.). O Brasil Colonial. Rio de Janeiro: Civilização Brasileira, 2014. 3 vols.

FRAGOSO, J.; GOUVÊA, M. F. (orgs.). Na trama das redes: política e negócio no império português, séculos XVI-XVIII. Rio de Janeiro: Civilização Brasileira, 2010.

FRAGOSO, J.; SAMPAIO, A. C. J. (orgs.). Monarquia pluricontinental e a governança da terra no ultramar atlântico luso: Séculos XVI-XVIII. Rio de Janeiro: Mauad X, 2012.

SAMPAIO, A. C. J.; ALMEIDA, C. M. C.; FRAGOSO. J. Conquistadores e negociantes: histórias de elites no Antigo Regime nos trópicos: América lusa, séculos XVI a XVIII. Rio de Janeiro: Civilização Brasileira, 2007.

VENÂNCIO, R. P.; GONÇALVES, A. L.; CHAVES, C. M. D. G. (orgs.). Administrando impérios: Portugal e Brasil nos séculos XVIII e XIX. Belo Horizonte: Fino Traç, 2012. 